(95\% confidence interval 4.68-10.71) had a benign diagnosis following lung resection (table 1).

False-positive pulmonary ${ }^{18}$ FDG uptake is well recognised and causes include a wide range of infections and inflammatory conditions, which occur because these processes are associated with increased glucose (and glucose analogue) metabolism. There are now $>40$ benign conditions that have been reported to show increased ${ }^{18}$ FDG uptake [2]. In a meta-analysis of PET for diagnosis of pulmonary nodules and mass lesions, ${ }^{18}$ FDGPET was demonstrated to have a sensitivity and specificity for malignancy of 96.8 and $77.8 \%$, respectively [3].

The reduced specificity of ${ }^{18}$ FDG-PET may become more important over time as there is an increasing incidence of adenocarcinoma related to a shift to consumption of low-tar cigarettes [4]. Adenocarcinoma of the lung is the most common peripheral lung cancer; therefore, an increasing incidence may result in more solitary pulmonary nodules. Solitary pulmonary nodules can represent a diagnostic challenge to respiratory physicians and radiologists, as their peripheral nature and small size sometimes prevent a tissue diagnosis via either bronchoscopy or percutaneous CT-guided needle biopsy. There are a number of reasons why not all patients can have a histological diagnosis prior to lung resection, including position and site of the tumour, and comorbid risks, such as emphysema.

The present audit demonstrates that the risk of a benign diagnosis at surgical resection for patients with a solitary pulmonary nodule suspicious of lung cancer, where no tissue diagnosis has been established following clinical assessment and radiological assessment, and multidisciplinary team review is approximately $8 \%$. Patients need to be advised of the risk of a benign diagnosis prior to surgical resection so that they can make an informed decision regarding undertaking this treatment, which is not without a mortality risk. The search for a more specific positron emission tomography tracer continues.

\section{I.J. Clifton, A.F. Scarsbrook and M.F. Muers}

Leeds Teaching Hospitals NHS Trust, Leeds, UK.

\section{STATEMENT OF INTEREST}

None declared.

\section{REFERENCES}

1 NICE. The Diagnosis and Treatment of Lung Cancer. London, National Institute of Clinical Excellence, 2005.

2 Kavanagh PV, Stevenson AW, Chen MY, Clark PB. Nonneoplastic diseases in the chest showing increased activity on FDG PET. AJR Am J Roentgenol 2004; 183: 1133-1141.

3 Gould MK, Maclean CC, Kuschner WG, Rydzak CE, Owens DK. Accuracy of positron emission tomography for diagnosis of pulmonary nodules and mass lesions: a metaanalysis. JAMA 2001; 285: 914-924.

4 Janssen-Heijnen ML, Coebergh JW. The changing epidemiology of lung cancer in Europe. Lung Cancer 2003; 41: 245-258.

DOI: $10.1183 / 09031936.00176708$

\title{
Smoking patterns in patients following a pulmonary embolism
}

\section{To the Editors:}

Tobacco smoking is a major risk factor for cardiovascular disease. It has been found that $30-40 \%$ of patients stop smoking spontaneously after the occurrence of serious cardiovascular events [1]. Pulmonary embolism is a potential lethal cardiovascular event, in which smoking behaviour has not yet been documented. Since patients surviving the acute embolus face an increased risk of arterial thrombotic events, i.e. myocardial infarction and stroke [2-4], the propensity to quit smoking following pulmonary embolism is of particular interest.

Our objective was to determine the impact of an episode of pulmonary embolism on smoking behaviour. We compared the fraction of smokers and the percentage of successful smoking cessation in pulmonary embolism patients with those in population-based controls.

Data from a large follow-up project of patients with pulmonary embolism were used for the analysis. All patients who had experienced acute pulmonary embolism between January 2001 and July 2007 at the Leiden University Medical Center (Leiden, the Netherlands) were eligible. All patients were invited to a control visit in our clinic. An accurate smoking history was collected, including the smoking status at the time of the pulmonary embolism and smoking behaviour after the pulmonary embolism. Smoking statistics of population controls were derived from a nationwide registry on smoking habits in the Netherlands. By means of a continuous study by request of the Dutch government, 200 randomly selected Dutch households were contacted weekly to assess their smoking behaviour [5]. For the analysis, we used the data derived from the period 2001-2007 from population controls aged $>20 \mathrm{yrs}$, because of the limited fraction of pulmonary embolism patients aged $<20$ yrs $(0.3 \%)$.

A total of 675 patients were diagnosed with pulmonary embolism during the study period. Of the 675 patients, 225 $(33 \%)$ died before they could be questioned. Also, 139 patients of the remaining $450(31 \%)$ did not give informed consent for the follow-up visit because of comorbidity, geographic reasons, impossibility to give informed consent due to psychiatric 
disease or aged $<18$ yrs or other reasons. The 311 study patients were interviewed $3.7 \pm 1.88$ yrs (maximum range 1.1-6.3 yrs) after the diagnosis. In total, 190 (61\%, 95\% confidence interval (CI) 55-67) patients confirmed a smoking history (active or former) at the time of pulmonary embolism, of whom $94(30 \%, 95 \%$ CI 25-36) patients were actively smoking. Out of these 94 patients, 32 (35\%, 95\% CI 25-45) had successfully quit smoking in the first year following the diagnosis. Overall, only two $(0.64 \%, 95 \%$ CI $0.08-2.3)$ patients started smoking after the diagnosis of pulmonary embolism. The percentage of quitters was not associated with age in the pulmonary embolism cohort.

Analysis of the control group showed that of the 117,100 population controls randomly selected between 2001 and 2007, $71,614(61 \%, 95 \%$ CI $60-61 \%)$ were current or former smokers and $34,177(29 \%, 95 \%$ CI $28-30 \%)$ were active smokers. There were no significant differences between the fraction of (active) smokers between the patients at the time of the pulmonary embolism and the controls (odds ratio (OR) 1.05, 95\% CI $0.82-1.34$ ). According to the registry, $4-5 \%$ (maximum) of the smokers were able to successfully quit yearly. If $5 \%$ was assumed, successful smoking cessation occurred in 1,709 of the 34,177 active smokers, which is significantly lower compared with the patient cohort ( $\mathrm{p}<0.001$; OR 10.3, 95\% CI 6.88-15.4).

Our data demonstrate that a pulmonary embolism is a signal to quit smoking in a significant proportion of patients (35\%), even without a specific intervention. In addition, randomly selected controls proved to have comparable smoking habits but a significantly smaller proportion of them was able to quit smoking successfully.

Our study has limitations. We could only interview patients who survived the pulmonary embolism and were willing to return to our hospital for a follow-up visit. Also, we have not verified with additional testing whether both the pulmonary embolism patients and the population controls actually stopped smoking. Nevertheless, all data were assessed prospectively in a large cohort. Further studies should focus on the reasons for smoking cessation, the relationship between smoking (cessation) and the occurrence of arterial thrombotic events in the clinical course of pulmonary embolism, and measures to further increase the number of patients quitting smoking.

\section{F.A. Klok*, I.C.M. Mos*, J.T. Tamsma*, K.W. van Kralingen and M.V. Huisman*}

*Section of Vascular Medicine, Dept of General Internal Medicine - Endocrinology, and "Dept of Pulmonary Medicine, Leiden University Medical Center, Leiden, The Netherlands.

\section{STATEMENT OF INTEREST}

None declared.

\section{REFERENCES}

1 Rigotti NA, Singer DE, Mulley Jr AG, Thibault GE. Smoking cessation following admission to a coronary care unit. J Gen Intern Med 1991; 6: 305-311.

2 Becattini C, Agnelli G, Prandoni P, et al. Prospective study on cardiovascular events after acute pulmonary embolism. Eur Heart J 2005; 26: 77-83.

3 Prandoni P, Ghirarduzzi A, Prins $\mathrm{MH}$, et al. Venous thromboembolism and the risk of subsequent symptomatic atherosclerosis. J Thromb Haemost 2006; 4: 1891-1896.

4 Sørensen HT, Horvath-Puho E, Pedersen L, Baron JA, Prandoni P. Venous thromboembolism and subsequent hospitalisation due to acute arterial cardiovascular events: a 20-year cohort study. Lancet 2007; 370: 1773-1779.

5 TNS NIPO. Continu Onderzoek Rookgewoonten 2001-2007. Personen van 15 jaar en ouder. Onderzoek in opdracht van STIVORO voor een rookvrije toekomst [Ongoing Study Smoking Habits 2001-2007. Persons Over 15 Years Old. Study by Request of STIVORO Towards a Smoke-free Future]. Amsterdam, TNS NIPO, 2008.

DOI: $10.1183 / 09031936.00182808$

\section{Poverty and tuberculosis: is it truly a simple inverse linear correlation?}

\section{To the Editors:}

JANSSENS and RIEDER [1] recently reported an inverse linear association between tuberculosis (TB) incidence and per capita gross domestic product, after analysing data from 171 World Health Organization (WHO) member states with paired data. We are in full agreement with the "take home" message that poverty alleviation must be an integral component of global TB control efforts. However, from an epidemiological perspective, additional factors may need to be considered to better understand the complex host-pathogen interplay at the population level.
Poverty facilitates the transmission of Mycobacterium tuberculosis, primarily through 1) its influence on living conditions, such as people living in overcrowded and poorly ventilated homes, 2) prolonged diagnostic delay and 3) increased vulnerability due to malnutrition and/or HIV infection [2, 3]. Although these ecological associations are widely recognised, it is frequently not supported by observations from individual studies. A potential explanation for this discrepancy is that beyond a certain threshold, the exact level of poverty has little influence on transmission risk, since living conditions remain conducive. The importance of living conditions rather than the exact level of poverty is supported by the rural/urban 